\title{
EL STATUS DE LA MUJER MIGRANTE. LAS MARROQUÍES EN ESPAÑA
}

\author{
Serena Vitale ${ }^{1}$
}

\section{RESUMEN}

La participación de las mujeres en los movimientos migratorios ha pasado desapercibida durante mucho tiempo, o se ha cristalizado, en particular con respecto a la emigración de mujeres magrebíes, en el tipo de una migración pasiva y una adaptación difícil a la sociedad occidental. Las mujeres que protagonizan el nuevo flujo inmigratorio de Marruecos a España, en cambio, parecen ajustarse a la sociedad española sin chocarse con fronteras rígidas, sin sentirse «fuera de lugar». Al mismo tiempo, actúan como transmisoras del cambio, negocian con sus familias, sobre todo con los hombres, los términos de la identidad nueva que van adquiriendo como consecuencia de la experiencia migratoria.

Palabras clave: mujeres, inmigración, Marruecos, España.

\section{SUMMARY}

Women's participation in migratory flows has gone unnoticed for a long time. In the case of women displacing from Magreb to Europe, the type of passive migration and hard adaptation to the Western society got crystallised. In the new immigration from Morocco into Spain, instead, women play a leading role. They seem to adjust quite easily to the Spanish society, and do not feel «out of their deep». At the same time, they pass on the change to their community, negotiate with their families - above all with men- the terms of the new identity they acquire as a consequence of migration.

Key words: women, inmigration, Morocco, Spain.

1 Becaria de la Universidad de Pisa (Italia), en el Departamento de Geografía Humana de la Universidad de Alicante (curso académico 1998-1999). Esta investigación se ha realizado en el marco del Proyecto SEC980628 . 


\section{Introducción}

El análisis de un fenómeno migratorio, como el de la inmigración marroquí en España, presupone la reconstrucción de aquello que definimos como un proceso migratorio, es decir, un acontecimiento complejo, articulado en al menos tres fases principales: la elección migratoria - tras la que se puede hallar un proyecto o una estrategia migratoria-, el propio hecho migratorio, y la experiencia de la migrante, en cuanto residente temporal o estable en el país de destino.

Este estudio, dedicado al status de la mujer y la especificidad de su experiencia migratoria, enfoca el momento del establecimiento en el país de destino. El objeto de la investigación es evaluar los cambios que se producen en la situación de las mujeres como consecuencia de la experiencia migratoria; en el trabajo de campo, me he concentrado en analizar su vida en España y compararla con la que llevaban o llevarían en Marruecos, tal como resulta de sus propios relatos. Hago referencia a testimonios directos recogidos mediante coloquios en profundidad con las inmigradas, y a una amplia información indirecta proporcionada por agentes que trabajan a diario con la población inmigrada.

La metodología que guía el trabajo es de tipo feminista, y nos permite destacar la autopercepción del cambio, aspecto a menudo desatendido. Por una parte, me parecía que un estudio sobre mujeres no debía prescindir de los correctivos proporcionados por la crítica feminista a las ciencias sociales. Eso no quiere decir que la Teoría Feminista sólo sea apropiada para estudios de género; al contrario, como rama especialmente dinámica e innovadora de la Teoría Crítica, representa un instrumento extremamente rico, sobre todo en el trabajo de campo.

La participación de las mujeres en los movimientos migratorios, interiores e internacionales, ha pasado desapercibida durante mucho tiempo. Las mujeres eran, como migrantes, invisibles, mejor dicho, transparentes ${ }^{2}$. Aunque el individualismo metodológico impusiese considerar al individuo como actor social, el «individuo» era inevitablemente de sexo masculino.

Cuando la familia se convierte en unidad de referencia, sí se incorpora la mujer en el cálculo, pero falta un efectivo reconocimiento de su papel, de su dignidad de «individua» y actriz social. Dentro de la familia, la mujer siempre se define en función de algún referente masculino: ella es madre, esposa, hija, hermana de un hombre, en la medida en que permanece el prejuicio del hombre jefe de hogar (Makinwa-Adebusoye, 1993). Esta visión distorsionada ha producido fallos graves en la comprensión de los fenómenos sociales (Bianco, 1991), y de las migraciones entre ellos.

Se argumenta, en ocasiones, que el patrón patriarcal es una aproximación fiable a la estructura de las sociedades estudiadas. Sin embargo, la antropología feminista no deja dudas que ese argumento se limita a superponer un prejuicio colonial a uno patriarcal, actuando de eco para lo que F. Mernissi define como el discurso sonoro sobre las mujeres, y callando su discurso propio (Mernissi, 1991).

En tiempos más recientes, entorno al enorme movimiento político e intelectual desencadenado por la Conferencia de Beijing de 1995, han empezado a difundirse estudios que destacan el papel de las mujeres jefas de hogar y analizan la feminización de la pobreza y las estrategias de supervivencia, con el objetivo de devolver una imagen más realista de la mujer.

2 La idea de transparencia contrapuesta a la de invisibilidad está en el texto de Marga Roig, 1999. 
Al mismo tiempo, la opinión pública y política occidental ha tenido que enfrentarse con nuevas inmigraciones mayoritariamente femeninas, cuyas protagonistas no encajaban en nada con el estereotipo conocido de migrante que sigue a su marido. Así que, con algo más de una década de retraso, las sociedades occidentales han empezado a ajustar cuentas con que, en las palabras de M. Morokvasic, «birds of passage are also women» (Morokvasic, 1984).

\section{2. ¿Mujeres fuera de lugar?}

La mayoría de los prejuicios — populares y académicos— alrededor de la inmigración femenina en Europa resulta de la experiencia de mujeres procedentes del mundo árabe: kurdas y turcas en Alemania, magrebíes en Francia y Bélgica, indias y pakistaníes en Gran Bretaña. La distancia cultural y la herencia colonial dificultaron la comprensión, por parte de los investigadores europeos, de la presencia e historia de estas mujeres. La Europa de entonces estaba todavía buscando una identidad propia, un desarrollo pacífico y unas vías posibles para la convivencia entre Oriente y Occidente; las mujeres de chilaba y pañuelo, criadas para no contradecir a los hombres ni mirarlos a los ojos, que apenas salían de casa y no lograban aprender idiomas extranjeros, en aquel contexto resultaban «fuera de lugar».

La inmigración femenina típica es la de las magrebíes, sobre todo argelinas, en Francia en los años setenta. Ésta sí era, en efecto, una following migration (inmigración-séquito) de maridos y padres que, desde la década anterior y recorriendo rutas tradicionales de los tiempos coloniales, se habían desplazado a Europa para cubrir la demanda de mano de obra del período de la reconstrucción post-bélica. La crisis petrolífera y la consecuente crisis financiera determinan un cambio repentino en la política inmigratoria de los países importadores de mano de obra extranjera, que se conoce como cierre de las fronteras. La nueva política restrictiva, unida a medidas favorables a la reagrupación familiar, se traduce en un poderoso incentivo «a quedarse», o sea adoptar un proyecto migratorio a largo o larguísimo plazo.

Las mujeres inmigrantes se convierten en protagonistas de un choque aparentemente irreconciliable, entre cultura árabe y occidental, sociedad «moderna» y «tradicional». Estudiando esta inmigración, y el papel de las mujeres en el mantenimiento o destructuración de las culturas propias del grupo migrante, I. Taboada-Leonetti distingue dos aptitudes típicas: la de las instrumentalistes y la de las promotionelles. Las instrumentalistes son más permeables a la cultura de la sociedad en que se insertan, sobre todo a los valores de emancipación femenina que las mujeres occidentales van reivindicando en aquellos años. A la vez, desde luego, viven la crisis de la deculturación, se ven obligadas a elegir o elaborar una síntesis entre valores nacionales y otros occidentales, o sea coloniales, a menudo en contradicción con sus propias familias, y con las mujeres de la familia. Las promotionelles se convierten de mujeres fuera de lugar a agentes privilegiadas del cambio, de lo que se llama, con o sin razón, integración (Taboada-Leonetti, 1983).

Sin embargo, en los últimos quince años han ocurrido cambios profundos, que influyen de manera significativa en todos los factores que pueden determinar y caracterizar un fenómeno migratorio. Por eso, la inmigración marroquí reciente a España, por el contexto histórico y político en que se desarrolla y el tejido social en que se inserta, representa un fenómeno nuevo y peculiar respecto a las migraciones tradicionales hacia Europa, en particular en lo que atañe al status de las mujeres. Conforme a las consideraciones expresadas y al trabajo de campo, voy a argumentar que las marroquíes en España tienen poco de «mujeres fuera de lugar». 


\section{Marroquíes en España}

El segundo proceso extraordinario de regularización iniciado en 1991 manifestó la magnitud de la presencia marroquí en España. En el primer proceso (julio 1985 - marzo 1986) los marroquíes presentaron el $18 \%$ de las solicitudes de regularización, es decir 7.868 de un total de 43.815. En 1991 el colectivo marroquí presentó el 43,2\% de las solicitudes, es decir 58.307 de 134.905. Puesto que en 1990 sólo había en España 16.665 residentes marroquíes, se contabilizaron 350 solicitudes de regularización por cada 100 residentes regulares (Gozálvez Pérez, 1998a).

El equipo del TEIM $^{3}$ ha analizado los expedientes de regularización para compilar el Atlas de la Inmigración Marroquí en España, 1996. Este trabajo, junto con unos artículos anteriores de los mismos autores y compiladoras, destaca la feminización de la migración marroquí a España: las mujeres son el 14\% de la población regularizada en 1991.

Sin embargo, el dato que nos interesa destacar no es la tasa de feminidad, que nada más mide numéricamente el peso relativo de la presencia femenina respecto a la masculina dentro del colectivo. Al contrario, dicha tasa hasta resulta baja en comparación con otras migraciones a España, por ejemplo la dominicana o la filipina (Solé, 1994; Gregorio Gil, 1996), conocidas por ser flujos casi exclusivos de mujeres. Lo importante es más bien el delinearse un proyecto y una trayectoria autónomos de las mujeres: «la idea más importante que se quiere destacar es que las mujeres no emigran porque emigren los hombres, y no están necesariamente en los sitios donde se concentran los hombres» (Ramírez, 1996b: 105).

La provincia de Madrid previsiblemente presenta la tasa de feminidad más alta, con el $38,6 \%$ de las marroquíes residentes en España, seguida por las provincias de Barcelona $(18,2 \%)$ y Málaga $(13,7 \%)$. Málaga, que casi iguala a Barcelona en número de mujeres, apenas alcanza un séptimo puesto en términos de inmigración marroquí en general (TEIM, 1996). La presencia de mujeres en Catalunya se ajusta más bien a patrones parecidos a los clásicos de la Francia de los setenta; en efecto, Catalunya fue a menudo una segunda elección, al encontrar «cerrada» la frontera con Francia (Colectivo Ioé, 1994).

En la provincia de Málaga las mujeres casi alcanzan la mitad (48\%) de la población regularizada, lo que se debe a una demanda laboral muy especializada y a la naturaleza laboral del propio proceso de regularización. Presumimos además que la distribución espacial diferencial por sexo se debe al funcionamiento de una red migratoria femenina específica y separada de la masculina. Cabe pensar, por fin, que las mujeres legalmente residentes en España gracias al trámite de la reagrupación familiar no pidieron un permiso de trabajo, lo que no implica que no estén trabajando fuera de casa, pero sí que no se han contabilizado en estas estadísticas (TEIM, 1996).

Tabla 1

UBICACIÓN LABORAL DE LAS MUJERES REGULARIZADAS EN 1991

\begin{tabular}{|l|r|}
\hline Servicio doméstico & $70,3 \%$ \\
Hostelería & $12,8 \%$ \\
Servicios & $5,9 \%$ \\
Otros sectores & $11 \%$ \\
\hline
\end{tabular}

FUENTE: TEIM, 1996, p. 106.

3 Taller de Estudios Internacionales Mediterráneos. 


\section{Una presencia en aumento}

Las cifras del proceso de regularización de 1991 señalan que el colectivo femenino más importante es el marroquí. A pesar de eso, su presencia pasa casi desapercibida, sea por la difusión de los datos relativos a la tasa de feminidad comparativamente baja, sea por que se consideran las inmigrantes procedentes de América Latina como un colectivo unitario, por lo que resulta el más numeroso. Por ejemplo, A. Izquierdo indica que «29 de cada 100 trabajadores regularizados fueron mujeres. En total 31.305 trabajadoras que procedían en su mayoría de América Latina (15.831) y del continente africano (8.396)» (Izquierdo, 1996: 119). Pero, desagregando los datos por nacionalidad en vez de por continente, el colectivo marroquí destaca con un $22 \%$ del total.

Tabla 2

NACIONALIDADES DE LAS TRABAJADORAS EXTRANJERAS REGULARIZADAS EN 1991

\begin{tabular}{|l|r|}
\hline Marruecos & 6.812 \\
República Dominicana & 4.737 \\
Perú & 3.170 \\
Argentina & 2.768 \\
Filipinas & 1.619 \\
Colombia & 1.306 \\
Resto & 10.839 \\
Total & 31.305 \\
\hline
\end{tabular}

FUENTE: A. Izquierdo, 1996, p. 119.

Es interesante averiguar la presencia marroquí en los stocks de trabajadoras no comunitarias en 1992 y 1993, y compararla con las cifras del segundo colectivo más importante, el de dominicanas. En 1992 las marroquíes siguen siendo algo menos del $20 \%$ de las trabajadoras no comunitarias en España, y descienden al 18\% el año siguiente. A pesar de la baja revelada por las fuentes oficiales, tanto Izquierdo como el Colectivo Ioé (1998a) estiman que ésta depende de la no renovación del permiso anual, y del regreso a la irregularidad de las trabajadoras inmigradas, más que de haber salido de España o dejado de trabajar.

Tabla 3

STOCK DE MUJERES TRABAJADORAS EXTRACOMUNITARIAS

\begin{tabular}{|l|c|c|}
\hline Nacionalidad & $\mathbf{1 9 9 2}$ & $\mathbf{1 9 9 3}$ \\
\hline Marruecos & 7.692 & 6.373 \\
República Dominicana & 4.651 & 4.449 \\
\hline Total & 40.147 & 34.642 \\
\hline
\end{tabular}

FUENTE: A. Izquierdo, 1996, p. 122. 
En septiembre de 1993, con ocasión del seminario Mujeres, democracia y desarrollo en el Magreb, W. Actis, del Colectivo Ioé, estimaba que «a pesar del predominio masculino, algo más del 25\% de la inmigración marroquí está compuesta por mujeres» (Actis, 1995: 125).

Según el Anuario de Estadísticas Laborales, 1995, las trabajadoras marroquíes pasan de 1.119 en 1989 a 6.990 en 1994 (datos al 31-XII-94), lo que quiere decir que el colectivo experimenta un fuerte incremento, tanto absoluto como relativo. «La proporción [femenina] respecto a la masculina es todavía baja, pero las estimaciones que la sitúan próxima al 20\% del total de inmigrantes magrebies no parecen desencaminadas» (Domingo Pérez, Viruela Martínez, 1996: 119).

La discrepancia entre datos y estimaciones se debe a que las estadísticas oficiales disponibles se refieren sobre todo a trabajadoras y exclusivamente a aquellas en situación regular, dejando sin contabilizar las trabajadoras a nero y las mujeres que no participan en el mercado del trabajo asalariado. Además, las estadísticas no siempre se desagregan por sexo, dejando así totalmente sumergida la presencia femenina en algunos fenómenos.

Cuando España aprueba la política de cupos, a partir de 1993, la participación de las mujeres en el fenómeno inmigratorio se hace más evidente. El contingente de 20.600 autorizaciones abierto en 1993 presentaba un índice de cobertura del 72\% para servicio doméstico y $20 \%$ para otros servicios a la persona, frente al $2 \%$ para agricultura y 0 puestos en la construcción. Se presentaron 6.000 solicitudes de permiso de trabajo, de las que 5.220 fueron resueltas positivamente, el 83\% (4.346) para puestos en el servicio doméstico (Gozálvez Pérez, 1998b). Manifiesta la fuerte segregación por sexo del sector, asumimos que la mayoría de estos permisos fueron concedidos a mujeres; y el colectivo marroquí cubrió un $11 \%$ del cupo. Así que la mujer inmigrada, la marroquí en particular, se convierte inesperadamente en protagonista de la política migratoria española.

El cupo de 1995 preveía 19.946 plazas, para las que se presentaron 37.124 solicitudes. Omitiendo las peticiones denegadas ${ }^{4}$, al colectivo marroquí se le concedieron 8.387 plazas $(42 \%), 1.785$ a mujeres $(21,3 \%)$. Si consideramos que el total de autorizaciones concedidas a mujeres fue 8.737, resulta que las marroquíes cubrieron en 1995 algo más del $20 \%$ del contingente femenino autorizado, y llegaron casi al 9\% del cupo total (Anuario de Migraciones, 1997).

Según los últimos datos disponibles del Colectivo Ioé, en 1997 las mujeres alcanzan el $33 \%$ de la población marroquí residente en España, y se confirman como el colectivo de mujeres inmigradas más numeroso. Las marroquíes son el 12,4\% de las extranjeras residentes en España, mientras otros colectivos asociados con inmigración económica - los latinoamericanos y el filipino- no alcanzan el 6\% (Colectivo Ioé, 1998b). Cabe recordar que manejamos datos oficiales, así que las cifras han de tomarse como indicativas; sin embargo, no hay por qué pensar que la importancia relativa de los colectivos está mal representada.

4 Éste es un caso en que no disponemos de datos desagregados por sexo. 


\begin{tabular}{|l|r|}
\hline Marruecos & $12,4 \%$ \\
Gran Bretaña & 12,2 \\
Alemania & 8,8 \\
Francia & 6,2 \\
Portugal & 5,9 \\
R. Dominicana & 5,5 \\
Perú & 4,7 \\
Argentina & 3,0 \\
Italia & 2,8 \\
Países Bajos & 2,6 \\
Filipinas & 2,5 \\
China & 2,4 \\
EE. UU. & 2,2 \\
Cuba & 2,2 \\
Colombia & 2,0 \\
Bélgica & 1,9 \\
\hline
\end{tabular}

FUENTE: Colectivo Ioé, 1998b, p. 19.

\section{Familias españolas, criadas marroquíes}

«El perfil medio de la inmigrante es el de una persona joven, soltera o divorciada, procedente de los suburbios de una ciudad marroquí, y que trabajó antes en Marruecos, bordando, como ayudante de administrativa, o como modista o dependienta, pero no necesariamente de manera regular. Su nivel de estudios es bajo, si bien lee y escribe en árabe, habla francés y lo puede leer» (Ramírez, 1995: 144). A pesar de los límites de las aproximaciones, la misma autora confirma que «en Cataluña parece tener bastante importancia el modelo de la mujer casada que vive con su marido» (ibídem), éste es el prototipo de la mujer marroquí en España. Donde existe una tradición de inmigración femenina más consolidada, por ejemplo en la franja urbana alrededor de Madrid, es característica la presencia de familias enteras (Pumares, 1996).

Conforme al trabajo de campo, deduzco que la tendencia a reconstituir en el país de inmigración núcleos familiares o de tipo familiar está difundida en cualquier zona afectada por el fenómeno inmigratorio, sobre todo cuando las protagonistas son mujeres. La reagrupación familiar es, a pesar de la dificultad del proceso burocrático por el que es preciso pasar, una vía de acceso para las jóvenes que piensan ponerse a trabajar, de forma más o menos «regular». Fuera de los límites legales estrictos de la reagrupación familiar, las familias actúan como cadenas migratorias especialmente fiables ${ }^{5}$, sobre todo para las mujeres. Los vínculos de parentesco son extensos y complejos, y en ocasiones hasta una vecina pasa a ser considerada una prima, procurando reconstruir de esta manera la red articulada de relaciones femeninas típica de las culturas mediterráneas.

5 La presencia de otras mujeres, normalmente ya casadas y más mayores, en el país de inmigración, es una garantía para la familia de la emigrante, en el sentido que confía en que se siga ejerciendo el control social (Ramírez, 1995; 1996a; en general con respecto al fenómeno, Hugo, 1997). 
Las inmigrantes marroquíes, como las latinoamericanas y filipinas, ocupan un nicho laboral bastante amplio, pero rígidamente definido. Como quedó evidente con la regularización de 1991, «las mujeres se concentran claramente en el servicio doméstico. (...) Su presencia en los otros sectores es simbólica» (Ramírez, 1996b: 106).

La demanda de servicio doméstico se originó en el área metropolitana madrileña, que históricamente hacía de polo de atracción para las jóvenes de escasos recursos que migraban del campo a la ciudad para trabajar de criadas. En la España del crecimiento económico las autóctonas están poco dispuestas a desempeñar esta tarea, de valoración social bajísima, y el oficio de criada va perdiéndose. En los ochenta, sin embargo, por las rápidas transformaciones por las que pasa la sociedad española, se crea una renovada demanda de mujeres para servicio doméstico.

Las mujeres españolas, que habían conseguido el acceso a la formación como sus colegas varones, empiezan a insertarse en el mercado del trabajo asalariado en calidad de profesionales (Solé, 1994). La salida de las mujeres del espacio doméstico genera una serie de alteraciones en la concepción y estructura de la familia española, especialmente evidentes en las grandes ciudades. La edad media de casamiento aumenta y el primer parto se aplaza, produciendo un descenso repentino de la tasa de natalidad; se detecta al poco tiempo el envejecimiento de la población. España llega tarde a la transición demográfica, pero la vive de manera veloz, y se coloca en una década o poco más - a falta de políticas de apoyo a las madres trabajadoras - por debajo de la tasa de recambio de la población. La nueva familia tipo española percibe dos sueldos, y sólo tiene uno o dos hijos para mantener; el nivel de ingresos sube de manera generalizada en los años ochenta y noventa y la calidad de la vida se reconceptualiza. Lo que no llega a cambiar es la asimetría entre los géneros, así que a las mujeres se les sigue atribuyendo las expectativas tradicionales de cuidado de la casa, los niños y los mayores. En la medida en que las mujeres ya no están dispuestas a hacerse cargo de estas tareas tradicionales, ni sus compañeros a repartirlas, «resulta más cómodo para toda la familia —varones y mujeres - recurrir al trabajo externo para las tareas domésticas, que distribuirlas y "pelearlas» entre los diferentes miembros, debido a la ruptura de patrones de conducta tradicionales según género a que ello conllevaría. Esto explica el aumento de la demanda del servicio doméstico por horas y el externo o a domicilio, para limpieza y cuidado de personas, en todos los niveles de la clase media» (Herranz Gómez, 1998: 72).

El proceso de regularización muestra las cifras de este mercado, ocupado por mujeres inmigradas de varias nacionalidades; luego la política de cupos empieza a producir un efecto distorsionante en el fenómeno migratorio, con la proporción de plazas para servicio doméstico del cupo que aumenta de año en año. Al mismo tiempo, el nicho laboral va asumiendo rasgos de ghetto, caracterizado, además de por la tradicional segregación por sexo, por una nueva segregación por procedencia.

\section{6. ¿Porqué emigran las mujeres? ${ }^{6}$}

El aumento progresivo del porcentaje de mujeres dentro del colectivo marroquí depende ampliamente del sistema de reclutamiento de mano de obra extranjera con que el Gobierno español pretende reglamentar el flujo migratorio. A medida que la demanda de trabajo en el servicio doméstico se amplía — sobre todo para cuidado de personas mayo-

6 Morokvasic, 1983 
res-, la política migratoria española perpetúa su impacto sexista ${ }^{7}$, en el país de origen y de destino. En Marruecos las familias se enteran de que las mujeres pueden encontrar trabajo más fácilmente que los hombres, y además con las garantías de un contracto y un permiso de trabajo, y eso las convierte en candidatas favoritas a la emigración dentro de una estrategia familiar. Las emigrantes se encargan de las remesas, y se muestran más puntuales y fiables que los hombres, jugando un papel importante la internalización de los valores de cuidado y responsabilidad hacia la familia, normalmente más profunda en las mujeres. Además, la emigrada se ve obligada a demostrar continuamente que sigue siendo una buena hija y una buena mujer según los estándares de su país, que no es una transgresora del orden social y que la única razón para quedarse en el extranjero es proporcionar a la familia una vida más acomodada (Ramírez, 1996a).

Las emigrantes se sienten estrictamente vinculadas, en cuanto mujeres, a preservar el honor de la familia con una conducta no criticable, aunque eso las obliga a penosas mediaciones. $S_{o a d}{ }^{8}$, nacida en 1980, en España desde hace casi siete años, me explica «Es que yo cuando me voy a Marruecos tengo que respetar la costumbre de allí. Mi hermana no, ella va con minifalda aquí y alli igual, con bikini y todo y la gente habla. Yo no. Igual, cuando hablo con amigas de mi madre, no digo lo que pienso, porque no quiero discutir, no quiero líos. Me adapto».

Las mujeres entrevistadas declaran haber decidido emigrar para poder trabajar, buscarse la vida, como me dicen; cualquier otra motivación aparece sólo de forma colateral o fugaz, lo que no quiere decir necesariamente que es menos importante.

Aicha*, nacida en 1975, procede de Larache y se encuentra en España desde 1993. Llegó sola, pero contando con el apoyo de una hermana mayor ya inmigrada. Vive en Elx, trabaja de ayudante de cocina en un restaurante y está a punto de comprar un piso con su novio, que es español. Cuando le pregunto por qué ha decidido emigrar, me da la respuesta que imagina me espero, "para trabajar»; después de un momento de titubeo añade que «la mujer aquí tiene más libertad». Aicha llegó con 18 años, sin acabar los estudios primarios, y nunca había trabajado en Marruecos; con su sueldo ahora mantiene a toda la familia, "por que allí nadie trabaja». Piensa quedarse en España para siempre, casarse y formar aquí una familia; cuando le pregunto si niñas y niños deberían recibir la misma educación, me contesta que no, que «las chicas hay que cuidarlas.... los padres, mejor que las cuiden».

Otro caso representativo es el de Suoad, nacida en 1970, procedente de Fez, que estudia en la Universitat de València. Licenciada y especializada en Filología Española por la universidad marroquí, ahora piensa quedarse en España y proseguir la carrera universitaria, posiblemente trabajar de profesora. A la pregunta de por qué ha decidido pedir la beca que la ha llevado a València me contesta «Es que no te he dicho algo: yo soy licenciada, pero es que en Marruecos no hay trabajo, hay montones de gente con títulos y están en la calle, en el paro, sin poder hacer nada». Trato de saber si estuvo buscando trabajo en Marruecos, y ella no me contesta ni sí ni no, sino me repite «es que no hay».

En el país de origen la estructura económica llega a producir impactos sexistas, que se insertan en un ambiente social en que las desigualdades de género están codificadas

7 Una ley o conjunto de normas y prácticas — lo que conocemos como «política»— pueden producir un trato o un impacto sexista. En caso de trato sexista, la discriminación por sexo es explícita e intencional, mientras que, en caso de impacto sexista, es más bien una consecuencia indirecta de las medidas adoptadas (England, 1997).

8 Utilizamos los nombres de las informantes cuando los conocimos, sino usamos nombres de fantasía y los indicamos con un *. 
jurídicamente. En las áreas de Marruecos donde se han instalado industrias export-oriented, sobre todo textiles y de manipulación de productos alimenticios, la mano de obra femenina se prefiere a la masculina, por presumirla más dócil y manejable. Además existe una censura social baja en el caso de despido de obreras, por considerarse el sueldo de la mujer todavía accesorio al del hombre, que es el cabeza de familia (Bernard, 1990). Las mujeres que trabajan en fábrica padecen una dura reprobación social, se les acusa de «tender a la prostitución» (Mernissi, 1991; Ramírez, 1995); a la vez, los hombres se quedan en el paro, sin poder cumplir con su papel de bread winners ${ }^{9}$ para las mujeres de la familia. Las tensiones sociales llegan a ser violentas, con algo de ensañamiento contra las mujeres que «se atreven» a aparecer en el espacio público, que ya ha dejado de ser prerrogativa exclusiva de los hombres (Bessis, Belhassen, 1992; Schaefer Davis, 1993).

La presión del entorno social puede más bien encaminar a las jóvenes — sobre todo solteras, viudas y separadas - hacia una elección migratoria, aunque sepan que en el extranjero sólo se les ofrece trabajar de domésticas.

Kabira, nacida en 1977, emigró a España en 1992, sin acabar los estudios primarios. Sus padres llevaban ya años en España, pero, según me cuentan, querrían que las tres hijas se quedasen en Marruecos estudiando. Kabira reivindica que decidió autónomamente emigrar, sin que nadie se lo sugiriese; al preguntarle por qué, me contesta: «Y ¿qué iba a hacer en Marruecos? ¿Quedarme en casa?».

Una de las primas, que llamaremos Naima*, quiere contarme su historia, pero habla sólo árabe, aunque esté en España desde 1996; Hannane, una hermana menor de Kabira, me hace de traductora. Naima* fue casada por su familia a los quince años, tuvo un hijo y se separó después de cinco años de matrimonio, volviendo con su hijo a la casa paterna. Allí se quedó durante unos tres años, y luego decidió emigrar y se reunió en Alacant con la familia de Kabira. Hannane me comenta que «Allí sólo podía estar en casa. Aquí trabaja».

Parece que las mujeres que tienen la intención de trabajar fuera del hogar —al menos en áreas donde existe una cultura de la migración - consideran más factible o más conveniente la opción de emigrar que la de buscar trabajo en Marruecos. La accesibilidad de empleo en el servicio doméstico influye, en una medida todavía por cuantificar, en la orientación de las mujeres hacia un proyecto migratorio, es decir, insertar la opción migratoria en su propio proyecto de vida. Estoy de acuerdo con A. Ramírez cuando, con respecto a la relación entre emigración y emancipación, dice: «No soy partidaria de que la emigración sea concebida por las mujeres como una manera de liberarse y alejarse de su sociedad, en la que se sienten oprimidas. El sentirse oprimida es una sensación que puede darse allí antes de salir, y en algún momento ellas piensan que en Europa será mejor, pero no es una razón para salir» (Ramírez, 1995: 148). La emigración femenina es, al fin y al cabo, básicamente de tipo económico, igual que la masculina; eso no implica que la profunda desigualdad que las mujeres viven en Marruecos no influya en sus decisiones, aunque de una manera que nos resulta difícil evaluar.

\section{El trabajo de las mujeres}

El trabajo parece ser la aspiración primaria de estas mujeres, aunque lo presentan a menudo como una necesidad. Trabajan de domésticas y sabían, al salir de Marruecos, que difícilmente encontrarían otro tipo de empleo. Es un trabajo muy duro, y además escasa-

9 Este papel del hombre está cultural y jurídicamente codificado en la sociedad marroquí; según la Mudawana, el marido debe proveer al mantenimiento de su esposa, proporcionandole la nafaqa; la esposa, en cambio, debe al marido obediencia. 
mente protegido, sobre todo en el caso del servicio interno ${ }^{10}$. A pesar de todo, se definen satisfechas, normalmente mantienen una buena relación con la señora y no piensan buscar otro empleo. Todas desean casarse —me contestan «iclaro!, ;ojalá!, jsi quiere Dios!»—, pero tienden a aplazar el momento del matrimonio ${ }^{11}, \mathrm{y}$, al pedirles que enumeren las características de un buen marido, incluyen que tiene que respetar a la mujer, además de ser trabajador. Me parece pertinente al respecto la observación de Roquero y Rodríguez, cuando notan en las marroquíes «la grata sorpresa de ver qué ocurre cuando las mujeres no están segregadas» (Roquero, Rodríguez, 1995: 65).

Disponer de dinero propio suele alterar la relación entre géneros dentro de la pareja y la familia (López, Ramírez, en prensa). Farida, por ejemplo, nacida en 1965, llegada a España en 1988 en el maletero de un coche, se casó en 1995 y, en cuanto pudo, «trajo» a su marido. Ahora residen en Parque Ansaldo, un barrio marginal en las afueras de Alacant, y tienen un hijo pequeño. El marido, al llegar, intentó reconstruir un patrón tradicional de familia, en el que Farida dejase de trabajar y tuviese más hijos. Al contrario, ella ha impuesto el uso de anticonceptivos y ha encontrado un trabajo que le permite quedarse en casa (cuida a una señora mayor que vive con ellos). En la larga charla que mantuvimos, Farida volvió a repetir que con su trabajo en España ha mantenido a toda la familia y que, después de casarse, ha encontrado un buen empleo para su marido. Por eso, él tiene que conformarse y respetarla. En este matrimonio es evidente la renegociación de los papeles tradicionales, que resulta, por ejemplo, de la diferente versión que los dos me ofrecen de los mismos acontecimientos. Cuando encontré a la pareja por primera vez, el marido me acogió con gran amabilidad, me invitó a volver en cualquier momento para entrevistarme con su mujer porque, según decía, "ella no trabaja: está en casa cuidando una abuela, no trabaja». Sólo con la entrevista pude enterarme de que «la abuela» no es una pariente, y que cuidarla le proporciona a Farida y su familia un ingreso de 120.000 ptas. mensuales.

\section{Femenina, plural}

Nos hemos planteado, al principio de este estudio, si las marroquíes en España son mujeres fuera de lugar, y en qué medida. La conclusión que propongo es que no, o al menos no se sienten ni se describen así.

Las mujeres con que he hablado piensan casarse en Marruecos, con un hombre marroquí, y celebrar una boda tradicional con toda la familia; pero planean vivir en España, y que sus hijos hablen árabe y español y sepan moverse entre las dos culturas. Con respecto a la educación de niñas y niños, algunas afirman que debe ser paritaria, otras van a perpetuar las desigualdades que a ellas se les enseñó. De todas formas, su proyecto migratorio, individual o familiar, es a larguísimo plazo, y el regreso a Marruecos no se contempla más que como una eventualidad remota.

Malika, nacida en 1974, madre de cinco hijas e hijos, en España desde 1993, dice: «Marruecos es bueno para ir de vacaciones. Para vivir, mejor España». Fatiha*, una prima suya nacida en 1959, fue casada por su familia a los 22 años, y el marido la trajo a vivir a Catalunya después de la boda, en 1981. Sueña con volver a Marruecos, pero sus seis hijas e hijos han nacido en España, y piensa que para ellos es mejor vivir aquí. Le

10 El servicio doméstico en España está bajo un Régimen Especial, así que las trabajadoras no están integradas en el Régimen General de la Seguridad Social.

11 Según la Mudawana, las mujeres tienen derecho a administrar sus bienes; pero lo normal es que dependan económicamente de un hombre, porque se quedan en casa o entregan su sueldo a los hombres de la familia. 
pregunto si le gustaría irse a otro país, y me contesta: «No. Si cambio país, es para volver al mío». Malika y Fatiha no han sido escolarizadas ni han trabajado nunca en su país; ahora viven en pisos ocupados del Parque Ansaldo, y reproducen en sus hogares dinámicas y relaciones domésticas lo más parecidas posible a las de Marruecos, donde «bajan» cada verano.

Otras mujeres elaboran un discurso propio en que aparece una clase de inquietud, como si salir de Marruecos fuese la única manera para crearse un espacio autónomo de decisión. Elaborando las conclusiones de R. Aparicio Gómez, diría que, en estos casos, podemos interpretar el hecho migratorio como una etapa - quizás un salto- dentro de una trayectoria biográfica ya divergente respecto a un sistema socio-cultural hegemónico (Aparicio Gómez, 1998), en el que hace falta poco para ser considerada —o considerarse— «divergente».

Farida dice: «Es que yo siempre he sido rebelde, porque quería mis derechos, y eso allí ya es ser rebelde». Soad expresa una inquietud parecida, aunque elaborada con respecto a su edad, cuando comenta: «Es que yo soy muy preguntona, ya verás; por eso, la escuela en Marruecos no me gustaba, porque sólo quieren mentalizarte, pero a mis preguntas no me contestaban. La gente en Marruecos es muy ignorante, confunden la religión con la costumbre, no tienen ni idea. Yo no tengo mucho estudio, pero leo mucho, y pregunto siempre, porque quiero aprender».

Ellas, como las otras, quieren quedarse en España para siempre, aunque eso no implique renunciar a su identidad árabe o musulmana. «El esfuerzo para constituir un discurso propio, que no pasa necesariamente por la síntesis equilibrada entre lo de allá y lo de acá, sino que muestra fracturas, fallas y rugosidades, es la característica principal que define la posición de estas mujeres» (Aparicio Gómez, 1998: 97).

Aunque exista en España una inmigración típica, de mujeres que han seguido a sus hombres, los flujos más recientes relacionados con la política de cupos son de tipo nuevo. Las marroquíes que llegan ahora son en su mayoría jóvenes solas, es decir, fuera de vínculos matrimoniales. Conforme a la experiencia que viven en España y a los contactos que establecen con la sociedad en que se insertan, se producen cambios de varia intensidad. Por una parte, son cambios producidos básicamente por la participación en el mercado del trabajo asalariado, que también podían producirse — como de hecho ocurre, en las grandes ciudades destino del éxodo rural- en Marruecos (CERED, 1994). El dato que interesa destacar es que las mujeres prefieren trabajar en el extranjero, donde se definen satisfechas con un empleo que no aceptarían nunca en su país, y que ya suelen llegar a España con la intención de quedarse. Por otra parte, hay cambios que derivan del contacto con una sociedad occidental y una cultura no árabe, y son igualmente importantes.

Las inmigrantes marroquíes parecen ajustarse a esas transformaciones, no padecen ningún choque cultural, no encuentran fronteras rígidas que separan sus dos mundos, y, por eso, no se las puede considerar de ninguna manera «fuera de lugar». Al mismo tiempo, actúan como transmisoras del cambio, negocian con sus familias, sobre todo con los hombres, los términos de esta identidad nueva que adquieren con la experiencia migratoria.

En cuanto protagonistas de la nueva inmigración marroquí en España, las mujeres merecen una atención especial, en particular para evitar que el servicio doméstico se convierta en el único espacio accesible para ellas. El reto del siglo que viene, para la sociedad española y sus responsables políticos, es el de una inmigración femenina y plural, cuyo impacto puede resultar un éxito o un fracaso según las vías de intervención escogidas. 


\section{Bibliografía}

ACTIS, Walter (1995): «Mujeres marroquíes en España. Algunos datos generales», en Martín Muñoz, Gema (comp.), Mujeres, democracia y desarrollo en el Magreb, Madrid, Pablo Iglesias.

APARICIO GÓMEZ, Rosa (dir.) (1998): Identidad y género: mujeres magrebies en Madrid, Dirección General de la Mujer, Consejería de Sanidad y Servicios Sociales, Comunidad de Madrid y Universidad Pontificia de Comillas, Madrid, B.O.C.M.

BERNARD, Chantal (1990): «Les femmes salariées et non salariées au Maghreb, des travailleuses à plein temps et 'hors du temps'», en Gadant, Monique - Kasriel, Michèle (dir.), Femmes du Maghreb au présent. La dot, le travail, l'identité, Centre National de la Recherche Scientifique, Centre Régional de Publication de Marseille, Paris, Editions du CNRS.

BESSIS, Sophie et BELHASSEN, Souhayr (1992): Mujeres del Magreb. Lo que está en juego, Madrid, Horas y Horas.

BIANCO, Maria Luisa (1991): «Quando nelle ricerche sulle classi sociali si prende in considerazione il genere», en Sociologia del Lavoro, n. 43.

CERED (1994): Femme et condition feminine au Maroc, 1994, Rabat.

COLECTIVO IOÉ (1994): Marroquins à Catalunya, Barcelona, Enciclopèdia Catalana.

COLECTIVO IOÉ (1998a): «La politique migratoire en Espagne après les élections de 1996», en Migrations Société, vol. 10, n. 57.

COLECTIVO IOÉ (1998b): «Mujeres migrantes en España. Proyectos migratorios y trayectorias de género», en Ofrim/Suplementos, Oficina Regional para la Inmigración de la Comunidad de Madrid, diciembre.

DOMINGO PÉREZ, Concepción y VIRUELA MARTÍNEZ, Rafael, (1996): «Mujeres del Magreb: situación y perspectivas migratorias», en «La inmigración magrebí en España: actualidad y futuro», Boletín de la Asociación de Geógrafos Españoles, n. 2.

ENGLAND, Paulina (1997): «Conceptualizing women's empowerment», En Female empowerment and demographic processes: Moving beyond Cairo, Seminario en la Universidad de Lund, 21-24 de abril de 1997.

GOZÁLVEZ PÉREZ, Vicente (1998a): «La percepción del Mediterráneo a través de la inmigración: las actitudes de los españoles hacia los magrebíes», en Investigaciones Geográficas, n. 20, Instituto Universitario de Geografía, Universidad de Alicante.

GOZÁLVEZ PÉREZ, Vicente (1998b): «Política de inmigración y presencia africana en la agricultura mediterránea de España», en Checa, Francisco (comp.), Africanos en la otra orilla. Trabajo, cultura e integración en la España mediterránea, Barcelona, Icaria.

GREGORIO GIL, Carmen (1996): Sistemas de género y migración internacional: la emigración dominicana a la Comunidad de Madrid, Madrid, Universidad Autónoma de Madrid.

HERRANZ GÓMEZ, Yolanda (1998): «Servicio doméstico y feminización de la inmigración en Madrid», en Ofrim/Suplementos, Oficina Regional para la Inmigración de la Comunidad de Madrid, diciembre.

HUGO, Graeme (1997): «Migration and female empowerment», in Female empowerment and demographic processes: Moving beyond Cairo, Seminario en la Universidad de Lund, 21-24 de abril de 1997.

IZQUIERDO ESCRIBANO, Antonio (1996): La inmigración inesperada. La población extranjera en España (1991-1995), Madrid, Trotta.

LÓPEZ GARCÍA, Bernabé y RAMÍREZ FERNÁNDEZ, Ángeles (en prensa), «Aixa y los lobos. Historia de una inmigrante», en Ágora Mediterránea, n. 1.

LÓPEZ GARCÍA, Bernabé (dir.); PLANET Ana y RAMÍREZ FERNÁNDEZ, Ángeles (coords.) (1996): Atlas de la inmigración magrebí en España, 1996, Madrid, Dirección General de Migraciones y Universidad Autónoma de Madrid.

LÓPEZ GARCÍA, Bernabé; PLANET Ana y RAMÍREZ FERNÁNDEZ, Ángeles, (1994). «Marroquíes en España: gestación, desarrollo y estructura de un colectivo inmigrante», en Desarrollo, Revista de la Sociedad Internacional para el Desarrollo, n. 24.

MAKINWA-ADEBUSOYE, Paulina (1993): «Labour migration and female-headed households», en Federici, Nora et al. (eds.), Women's position and demographic change, Oxford, Calendon Press. 
MOORE, Henrietta L. (1991): Antropología y feminismo, Madrid, Cátedra.

MERNISSI, Fátima (1991), Marruecos a través de sus mujeres, Madrid, Ediciones del oriente y del mediterráneo.

MOROKVASIC, Miriana, (1983): «Why do women emigrate? Towards understanding of the sexselectivity in the migratory movements of labour», in Studi Emigrazione/Migration Studies, XX, n. 70 .

MOROKVASIC, Miriana (1984): «Birds of passage are also women...», en International Migration Review, vol. 18, n. 4, Center for Migration Studies, Staten Island, NY.

PUMARES, Pablo (1996): La integración de los inmigrantes marroquíes. Familias marroquíes en la Comunidad de Madrid, Barcelona, Fundación La Caixa.

RAMÍREZ FERNÁNDEZ, Ángeles (1995): «Las inmigrantes marroquíes en España. Emigración y emancipación», en Martín Muñoz, Gema (comp.), Mujeres, democracia y desarrollo en el Magreb, Madrid, Pablo Iglesias.

RAMÍREZ FERNÁNDEZ, Ángeles (1996a): El análisis del origen en las migraciones: redes migratorias entre España y Marruecos, Madrid, Taller de Estudios Internacionales Mediterráneos, Universidad Autónoma de Madrid.

RAMÍREZ FERNÁNDEZ, Ángeles (1996b): «Las inmigrantes marroquíes en el proceso de regularización», en TEIM, Atlas de la inmigración magrebí en España, 1996, Madrid, Dirección General de Migraciones y Universidad Autónoma de Madrid.

ROIG, Marga (1999): «La mujer y el poder», en CGT, Rojo y negro, Cuarta Época, Año X, n. 109. ROQUERO, Esperanza y RODRÍGUEZ, Pilar (1995): La diversidad de las mujeres migrantes: El caso de la ciudad de Granada, Madrid, Instituto de la Mujer, Ministerio de Asuntos Sociales.

SCHAEFER DAVIS, Susan (1993): «Changing gender relations in a Moroccan town», en Tucker, Judith G. (ed.), Arab women. Old boundaries, new frontiers, Indiana UP.

SOLÉ, Carlota (1994): La mujer inmigrante, Madrid, Instituto de la Mujer, Ministerio de Trabajo y de Asuntos Sociales.

TABOADA-LEONETTI, Isabelle (1983): «Le rôle des femmes migrantes dans le maintien ou la destructuracion des cultures nationales du groupe migrant», en Studi Emigrazione/Migration Studies, XX, n. 70. 